\section{Laser-Induced Breakdown Spectroscopy (LIBS) Quality Control and Origin Identification of Handmade Manufactured Cigars}

\author{
Fernando C. Alvira, ${ }^{a, *}$ \\ Gabriel M. Bilmes, ${ }^{a, b}$ Teresa Flores, ${ }^{c}$ \\ Luis Ponce ${ }^{c}$ \\ a Centro de Investigaciones Opticas (CONICET- \\ CICPBA), Camino Centenario e/505 y 508, $1897 \mathrm{La}$ \\ Plata, Argentina \\ b Universidad Nacional de La Plata, Facultad de \\ Ingenieria, 1900 La Plata, Argentina \\ c Instituto Politécnico Nacional, CICATA-ALTAMIRA, \\ Carretera Tampico-Puerto Industrial Altamira, Km \\ 14.5, 89600 Altamira, Mexico
}

Tobacco is an agricultural product originating in America that is obtained by processing the leaves of various plants of the genus Nicotiana tabacum. It is the inedible product occupying the most plantings in the world, according to a recent report from the United Nations Food and Agriculture Organization. It is consumed in various ways, but the most popular form of consumption is, undoubtedly, by smoking cigarettes. A particular segment of the tobacco industry is the manufacturing of handmade cigars, which for some third-world countries is an important source of income. There are different qualities of cigars, and a major problem is the adulteration that occurs, for example, when authentic high-quality leaves are replaced by lower quality leaves. A factor that influences the quality of the cigars is the smoke combustion process, which depends on several factors, particularly the composition of the leaves. We present a simple and quick technique for the quality control and origin identification of handmade cigars that measures the $\mathrm{Mg} / \mathrm{Ca}$ ratios in the tobacco leaves and wrappers of the cigars using laser-induced breakdown spectroscopy.

Index Headings: Handmade cigars; Tobacco analysis; Laserinduced breakdown spectroscopy; LIBS; Magnesium-Calcium analysis; $\mathrm{Mg}-\mathrm{Ca}$ analysis.

\section{INTRODUCTION}

Tobacco is an agricultural product originating in the Americas and processed from the leaves of various plants of the genus Nicotiana tabacum. It is consumed in several ways, but the main one is undoubtedly combustion for smoking. Tobacco is composed of an alkaloid

Received 2 March 2015; accepted 1 April 2015.

* Author to whom correspondence should be sent. E-mail: fcalvira@ ciop.unlp.edu.ar

DOI: $10.1366 / 15-07935$ named nicotine, which is found in the leaves in variable proportions (from $<1$ to $12 \%$ ).

The handmade cigar industry is an important source of income, as well as an essential part of tradition and national culture for various countries. ${ }^{1}$ Tobacco contains a number of chemical compounds that affect its quality: Polyphenols and carbonyls play an important role in the flavor and aroma, cellulose and mineral materials are decisive for combustion, and glucosides cause the bitter taste in the leaves and in the final product. Of the elements present in the leaf, potassium is a major constituent of the ash that results from continuous combustion without flame. The elements $\mathrm{Mg}$ and $\mathrm{Ca}$ have a decisive influence on the incineration process. ${ }^{2}$ When $\mathrm{Ca}$ is in excess, the result is a compact ash that hinders the passage of air into the cigar, resulting in incomplete combustion. By contrast, the presence of $\mathrm{Mg}$ produces a porous and light-colored ash, which improves combustion. ${ }^{3}$ Acidic compounds of ash, chlorine, phosphorus, silicon, and sulfur in general tend to retard combustion. However, it is important to emphasize that the quality of the combustion depends primarily on the preparation of the cigar, which is what ultimately ensures proper airflow, and this depends primarily on the manufacturer's ability and experience.

Thus, monitoring the composition of the tobacco leaves is very important in all phases of the production process. In large cigarette companies, this has been solved because most of them are equipped with adequate quality-control laboratories that include several complex and costly instruments. The mineral composition is usually determined using atomic absorption, atomic emission or X-ray spectrometry. ${ }^{4-6}$ The organic components can be determined using gas chromatography, high-performance liquid chromatography, or infrared spectrometry. ${ }^{7}$ However, none of those instruments allows a quick, easy, and elemental determination in the field.

In the case of handmade cigar manufacturing, in which a relatively short-scale production of specific kinds of cigars prevails, it is more difficult to get access to highcost analytical techniques. Nevertheless, the handmade cigar industry is particularly sensitive to the quality of the leaf plantations and to the use of fertilizers and other chemicals that supply the industry. For those reasons, it would be desirable to control the raw-material production before these raw materials enter the production plant; thus, it is necessary to have analytical techniques that are simple, inexpensive, and can ideally be used by operators without high-level training.

The inherent characteristics of laser-induced breakdown spectroscopy (LIBS) make it a good candidate to solve this problem. Compared to many other types of elemental analyses, LIBS is an appealing technique because setting up the apparatus to perform the measurements is, in principle, very simple. Because it 


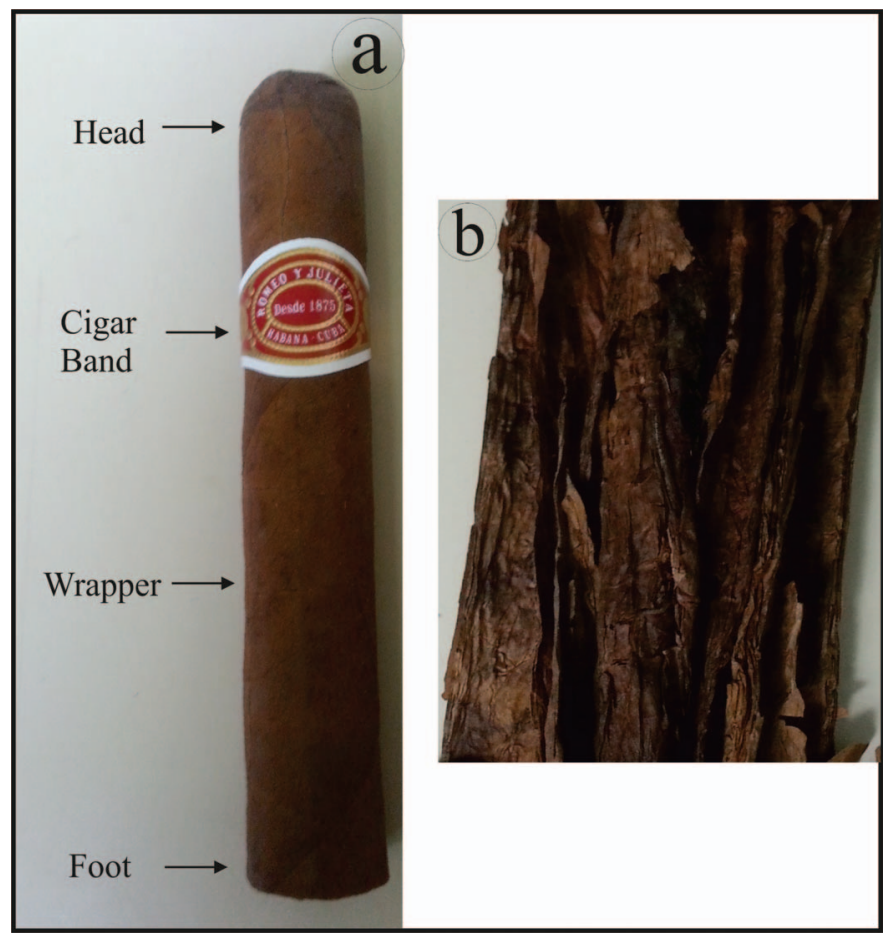

FIG. 1. (a) Outside parts of a cigar. (b) Dried bunches of leaves inside a cigar.

requires no previous sample preparation, LIBS has no limitations in terms of sample dimensions and shapes. The analysis is micro-destructive, and only a small quantity of the sample is needed, with minimal damage done to the sample. Chemical imaging of surfaces such as spatial distribution profiles and depth profiling allows mapping and layer-by-layer characterization of the composition of the surface as well as the substrate..$^{8-11}$ Although LIBS has been applied several times to the analysis of vegetable material, it has not been applied to tobacco analysis before. ${ }^{12-14}$

In this article, we develop a simple and quick technique based on LIBS that uses the $\mathrm{Mg} / \mathrm{Ca}$ ratio in the tobacco leaves and the wrapper of the cigars for the quality control and origin identification of handmade manufactured cigars.

\section{EXPERIMENTAL}

The configuration we used has been published elsewhere, ${ }^{15}$ and just a quick description is provided here. The ablation process was carried out by a neodymium-doped yttrium aluminum garnet (Nd:YAG) Ara laser (Bralax Laser Labs), capable of delivering pulses of $40 \mathrm{~mJ}$ at $10 \mathrm{~ns}$ pulse width with a repetition rate of $2 \mathrm{~Hz}$. The laser beam was focused on the sample using a $15 \mathrm{~cm}$ focal length lens. The energy of the laser pulse was controlled so that it had laser fluences up to $15 \mathrm{~J} / \mathrm{cm}^{2}$. For the analysis of the plasma emission, we used a system composed of an optical fiber attached to a cross Czerny-Turner miniature spectrometer (Ocean Optics) with a linear charge-coupled device (2048 pixels). This spectroscopic setup enabled the simultaneous detection of a large spectral region (from 250 to $1100 \mathrm{~nm}$, with a $0.3 \mathrm{~nm}$ spectral resolution) in a single laser shot. The detection was done at $90^{\circ}$ with respect the excitation laser.

In a typical cigar, five parts can be distinguished. The head is the region that goes in the smoker's mouth (Fig. 1a). The cigar band is a paper band that identifies the type and brand of cigar. The wrapper is a spirally rolled leaf of tobacco that covers the cigar, and the foot is the end meant to be lit. The fifth part is the dried bunches of leaves that are inside, shown in Fig. $1 \mathrm{~b}$.

We analyzed 10 brands of cigars from five countries, as detailed in Table I. To ensure the reproducibility of the results, for each brand at least 10 different cigars were analyzed, which were from different years of production and had been acquired in different places. For example, the Cuban cigars we studied were acquired in stores in Cuba, Argentina, and Mexico; similarly, the Nicaraguan cigars were obtained from stores located in Argentina, the United States, and Mexico. All the cigars in the study were manufactured at different times. For each cigar, we took measurements of both the tobacco leaves and the wrapper. For this purpose, the cigars were carefully disassembled and $3 \mathrm{~cm}$ sections of the leaves were selected.

\section{RESULTS AND DISCUSSION}

The LIBS spectra were obtained by using single shots with fluences above the ablation thresholds $\left(3 \pm 1 \mathrm{~J} / \mathrm{cm}^{2}\right)$ of the tobacco leaves and the wrapper. Once the ablation threshold is known, it is best to use a slightly greater fluence than the threshold to minimize the laser requirements, allowing the use of cheaper and more compact equipment. In all cases, a first shot was used to clean the surface.

Figure 2 shows a typical multiline spectrum obtained for the wrapper tobacco leaves of the cigars. As

TABLE I. Summary of $\mathrm{Mg} / \mathrm{Ca}$ ratios results.

\begin{tabular}{|c|c|c|c|c|}
\hline Brand & Country of origin & $(\mathrm{Mg} / \mathrm{Ca})_{\text {wrapper }}$ & $(\mathrm{Mg} / \mathrm{Ca})_{\text {leaves }}$ & $(\mathrm{Mg} / \mathrm{Ca})_{\text {leaves }}+(\mathrm{Mg} / \mathrm{Ca})_{\text {wrapper }}$ \\
\hline Cohiba & Cuba & $0.30 \pm 0.02$ & $0.23 \pm 0.02$ & $0.53 \pm 0.04$ \\
\hline Romeo y Julieta & Cuba & $0.31 \pm 0.02$ & $0.28 \pm 0.02$ & $0.59 \pm 0.04$ \\
\hline Montecristo & Cuba & $0.31 \pm 0.03$ & $0.31 \pm 0.02$ & $0.62 \pm 0.05$ \\
\hline Bucanero & Nicaragua & $0.33 \pm 0.03$ & $0.34 \pm 0.03$ & $0.67 \pm 0.06$ \\
\hline Rosario & Mexico & $0.36 \pm 0.03$ & $0.37 \pm 0.01$ & $0.73 \pm 0.04$ \\
\hline AT & Nicaragua & $0.40 \pm 0.04$ & $0.37 \pm 0.02$ & $0.77 \pm 0.06$ \\
\hline Francisco Miranda & Dominican Republic & $0.36 \pm 0.02$ & $0.41 \pm 0.02$ & $0.77 \pm 0.04$ \\
\hline Josefina & Brazil & $0.36 \pm 0.02$ & $0.42 \pm 0.02$ & $0.78 \pm 0.04$ \\
\hline Doña Flor & Brazil & $0.45 \pm 0.03$ & $0.37 \pm 0.02$ & $0.82 \pm 0.05$ \\
\hline 1922 & Nicaragua & $0.40 \pm 0.04$ & $0.44 \pm 0.02$ & $0.84 \pm 0.06$ \\
\hline
\end{tabular}




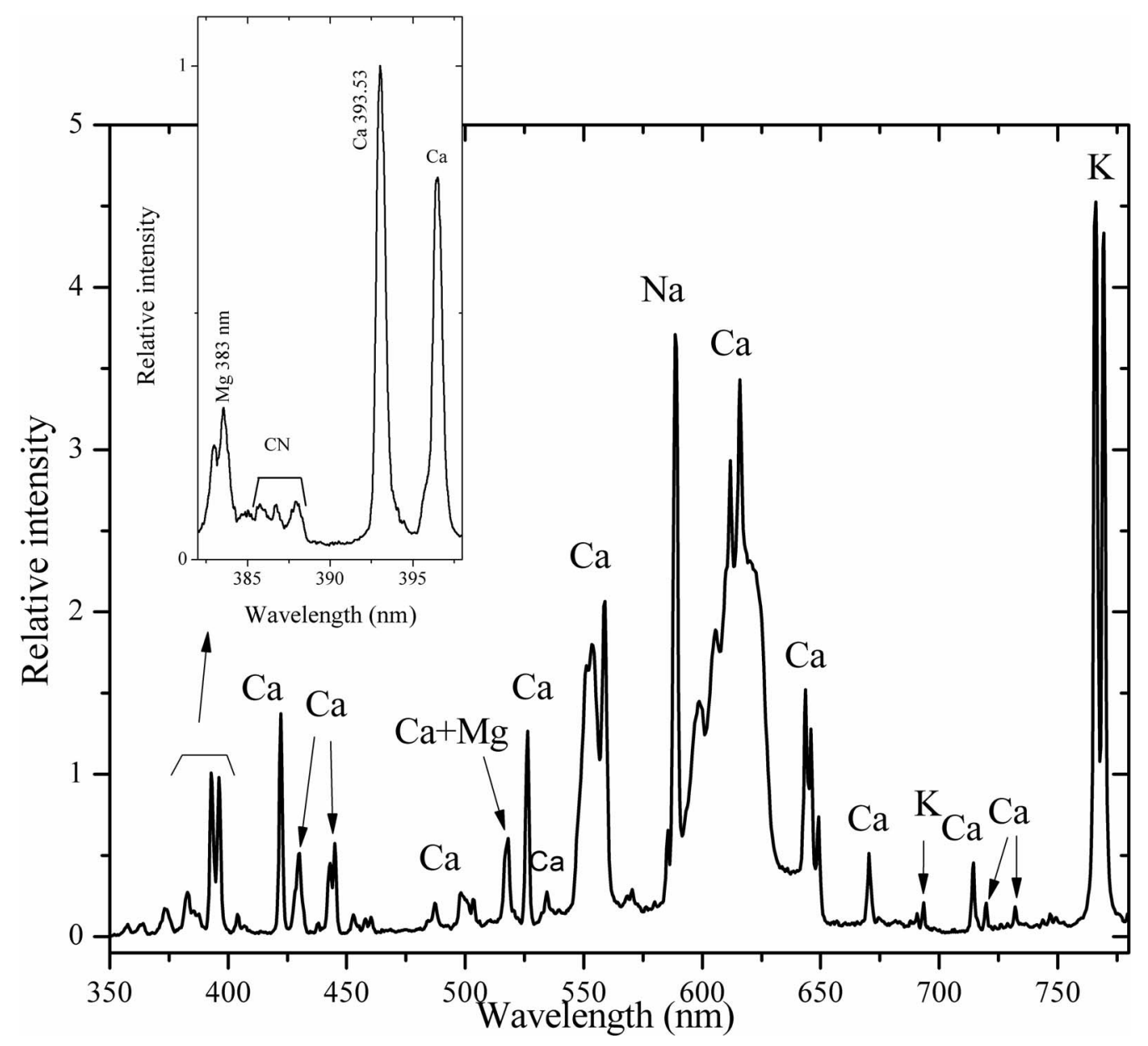

FIG. 2. Typical spectrum of tobacco. Inset: The Mg and Ca characteristic lines used for measurements.

expected, characteristic lines for $\mathrm{Mg}, \mathrm{Ca}, \mathrm{Na}$, and $\mathrm{K}$ are clearly observed. The presence of these elements is related to several variables. Magnesium is part of the pyrrolidine ring of the chlorophyll, and the other elements are related to the metabolic processes of the vegetable cell. In the case of tobacco leaves, these elements could also come from the soil and fertilizers (if employed during the process of growing the plant). The elements $\mathrm{K}$ and $\mathrm{Na}$ are closely related to the mechanism used by cells to obtain energy.

With the aim of measuring the $\mathrm{Mg} / \mathrm{Ca}$ ratio in the set of samples, we selected representative characteristic lines of these two elements. The inset in Fig. 2 shows the spectral region between 382 and $398 \mathrm{~nm}$, in which the lines of $\mathrm{Mg} \mathrm{I}(382.9,383.2$, and $383.8 \mathrm{~nm})$ and $\mathrm{Ca}$ II (393.4 $\mathrm{nm}$ ) were identified. We chose these lines because they are very close in wavelength and, consequently, any change related to the absolute intensity of both lines would not be important.

It was previously demonstrated for other materials that the temporal evolution and the decay kinetics of the $383 \mathrm{~nm}$ lines of $\mathrm{Mg}$ and the 393.4 lines of $\mathrm{Ca}$ are the same. $^{9}$ By using a setup with a programmable time delay we confirmed this result for the cigar samples. Figure 3 shows the temporal evolution of the $383 \mathrm{~nm} \mathrm{Mg}$ lines compared with the $393.4 \mathrm{~nm} \mathrm{Ca}$ II line. As we can see, this behavior ensures that, independent of the temporal delay used when the signal is acquired, the
$\mathrm{Mg} / \mathrm{Ca}$ ratio will be constant. To avoid bremsstrahlung and to have a better signal-to-noise ratio in the spectrum, we made the measurements with a delay of less than $1 \mu$ s.

Determination of the Magnesium to Calcium Ratios in Tobacco Leaves and Wrappers. For each cigar, LIBS spectra were obtained in 10 different regions of both the wrapper and the tobacco leaves. In all cases, the first laser pulse was used to clean the analyzed region. After that, no significant changes were observed among spectra from pulse to pulse. Then, the 10 spectra were averaged for a better signal-to-noise ratio.

The presence of $\mathrm{Mg}$ relative to $\mathrm{Ca}$ was determined from the averaged spectra of the tobacco leaves and wrapper of each cigar by measuring the ratio of the line intensities $I_{\mathrm{Mg}(383) /} / \mathrm{Ca}$ (393). Table I shows the mean values and dispersion of the $\mathrm{Mg} / \mathrm{Ca}$ ratio in the wrapper and the tobacco leaves for the 10 cigars studied.

As we can see, the three brands of Cuban cigars have the lowest $\mathrm{Mg} / \mathrm{Ca}$ ratios in both their wrapper and tobacco leaves, followed by one brand from Nicaragua and one brand from Brazil. For these brands, the behavior of the $\mathrm{Mg} / \mathrm{Ca}$ ratios for the wrapper and leaves are similar. The rest of the brands have higher values of $\mathrm{Mg} / \mathrm{Ca}$. Figure 4 shows the total $\mathrm{Mg} / \mathrm{Ca}$ ratio intensity bar graphs, defined as $(\mathrm{Mg} / \mathrm{Ca})_{\text {leaves }}+(\mathrm{Mg} / \mathrm{Ca})_{\text {wrapper }}$ for the 10 brands of cigars. The corresponding values and uncertainty can be found in the last column of Table I. 


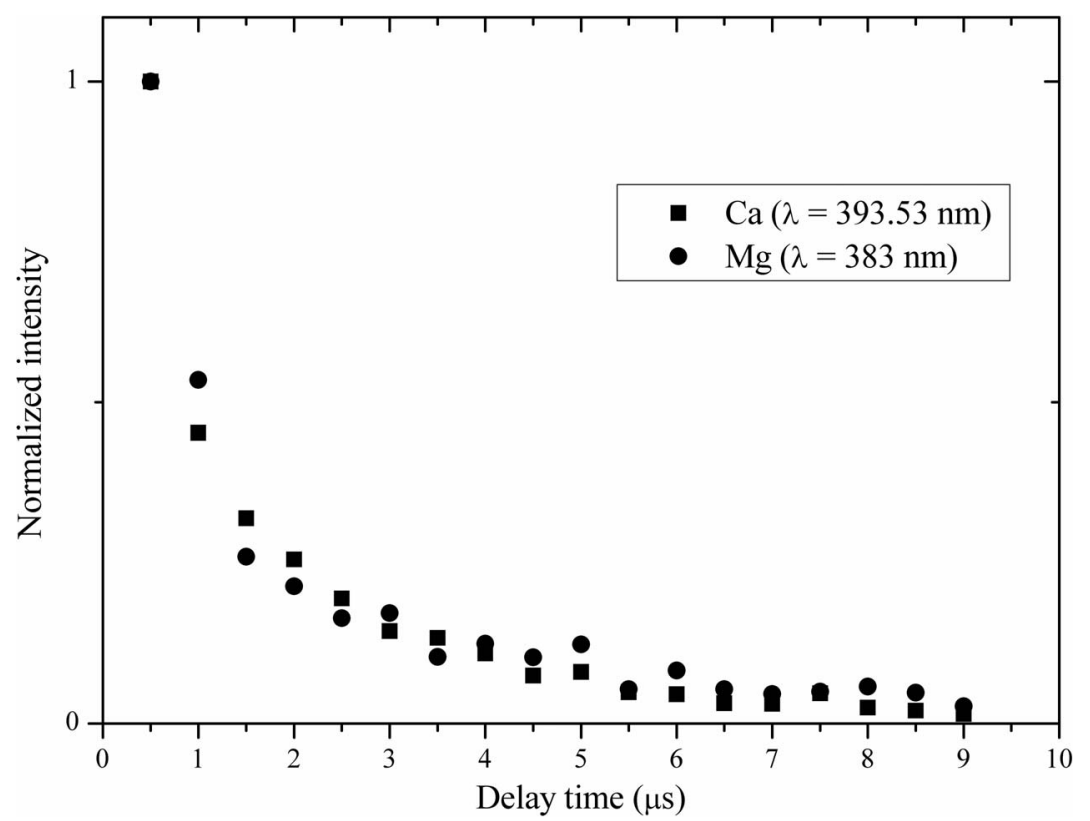

FIG. 3. Intensity of the $\mathrm{Mg}$ and $\mathrm{Ca}$ lines as a function of time; the integration time was set to $30 \mu \mathrm{s}$.

From this result for this sample set, we propose that the total $\mathrm{Mg} / \mathrm{Ca}$ ratio (the sum of the $\mathrm{Mg} / \mathrm{Ca}$ ratios of the leaves and wrapper) can be used as a characteristic reference value to identify the origin of the cigar as well as a quality-control parameter in the production process of the cigars.

\section{CONCLUSION}

Based on LIBS, we have developed a simple and fast technique for the quality control and identification of the origin of handmade manufactured cigars. By measuring the $\mathrm{Mg} / \mathrm{Ca}$ ratio in the wrapper and the tobacco leaves,

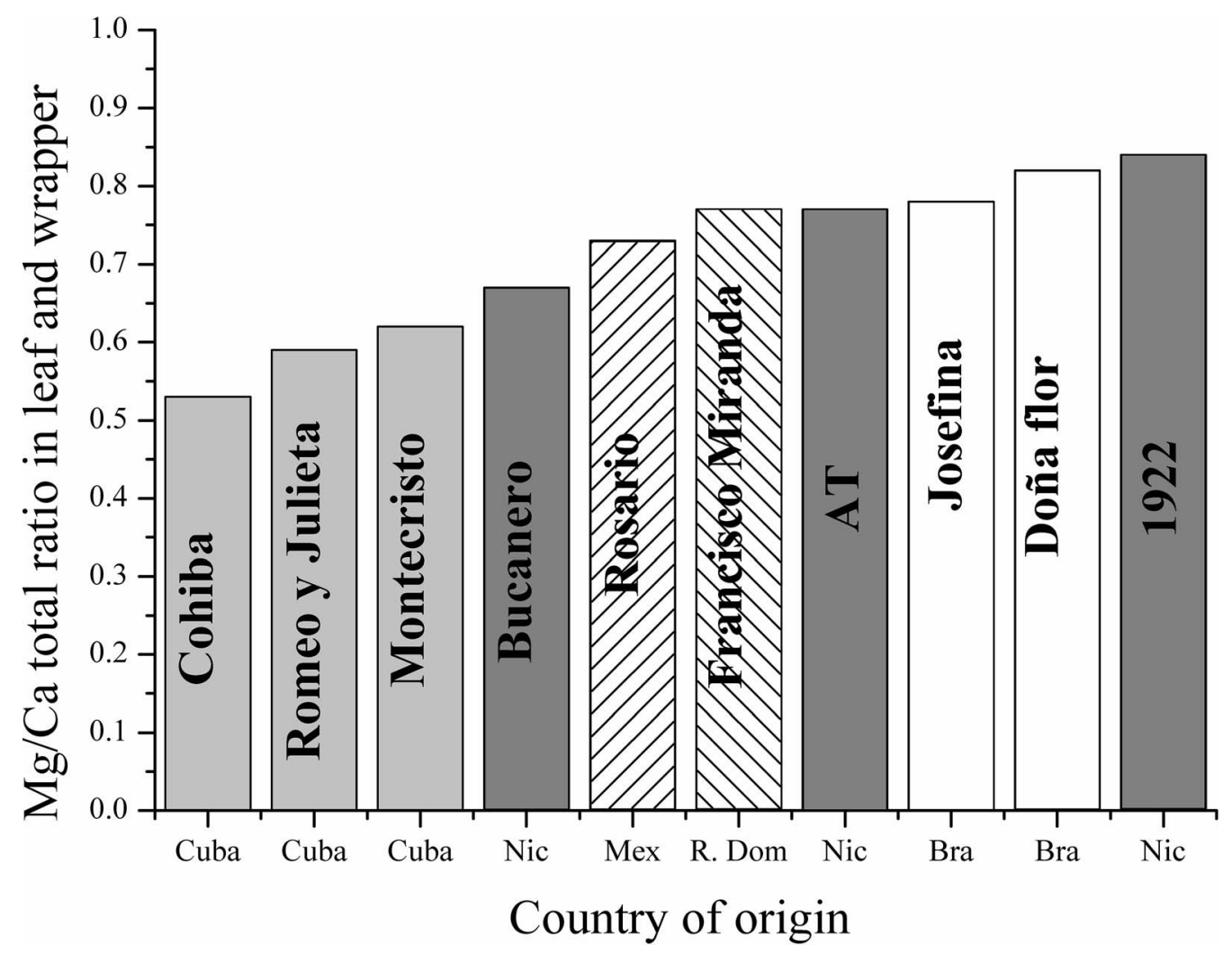

FlG. 4. Total Mg/Ca ratio intensity bar graphs, defined as $(\mathrm{Mg} / \mathrm{Ca})_{\text {leaves }}+(\mathrm{Mg} / \mathrm{Ca})_{\text {wrapper }}$ for the 10 brands of cigars. Bra, Basil; Mex, Mexico; Nic, Nicaragua; R Dom, Dominican Republic. 
characteristic reference values of this parameter for each brand of cigar can be obtained.

In addition, using a portable LIBS device, this method allows the monitoring of the origin of cigar leaves. The $\mathrm{Mg} / \mathrm{Ca}$ ratios of the cigar leaves can be compared to the ratios in the plantation leaves.

As is well known, Cuban and Nicaraguan cigars are recognized by smokers as the finest cigars in the world. This is in agreement with the results we obtained, which show that all the Cuban brands and one of the most recognized Nicaraguan brands have the lowest $\mathrm{Mg} / \mathrm{Ca}$ ratios compared to other cigars. Although there is no absolute indicator of the quality of handmade cigars, in that this factor is highly subjective, the $\mathrm{Mg} / \mathrm{Ca}$ ratio may be taken as a parameter for the recognition of the highest-quality brands.

\section{ACKNOWLEDGMENTS}

This study was partially supported by the Consejo Nacional de Investigaciones Científicas y Técnicas (CONICET)-Consejo Nacional de Ciencia y Tecnologia (CONACYT) International Cooperation Project and I143-UNLP from Argentina. FCA wishes to thank the Latin America Physics Center (CLAF) for financial support. This study was also supported by CONACYT through project 190591. FCA is a researcher with CONICET. GMB is a researcher with Comision de Investigaciones Científicas de la Provincia Buenos Aires (CIC-BA).

1. R.C. Guerrero. "Origen e Historia del Tabaco". El Cultivo del Tabaco. San José, Costa Rica: Editorial Universidad Estatal a Distancia, 1995. Pp. 3-12.

2. D.L. Davis, M.T. Nielsen, Eds. Tobacco : Production, Chemistry, and Technology. Malden, MA: Blackwell Science, 1999. Pp. 265-284.

3. N. Lugon-Moulin, F. Martin, M.R. Krauss, P.B. Ramey, L. Rossi. "Cadmium Concentration in Tobacco (Nicotiana tabacum L.) from Different Countries and Its Relationship with Other Elements". Chemosphere. 2006. 63(7): 1074-1086.

4. S. Qin, Z.-Y. Wang, J.-X. Shi. "Quality Characteristics of Tobacco Leaves with Different Aromatic Styles from Guizhou Province, China”. Agric. Sci. China. 2007. 6(2): 220-226.
5. P. Masson. "Imaging of Elements in Leaves of Tobacco by Solid Sampling-Electrothermal Vaporization-Inductively Coupled Plasma-Optical Emission Spectrometry". Spectrochim. Acta, Part B. 2014. 102(1): 24-27.

6. M. Bulbul, P. Unak, A.R. Sisman, C. Coker. "Blood Levels of Cd, Pb, $\mathrm{Cu}, \mathrm{Zn}, \mathrm{Fe}, \mathrm{Mg}, \mathrm{Ca}$ and $\mathrm{P}$ in Tobacco Workers". Fresen. Environ. Bull. 2006. 15(12A): 1477-1483.

7. T. Kakie. "Phosphorus Fractions in Tobacco Plants as Affected by Phosphate Application". Soil Sci. Plant Nutr. 1969. 15(2): 81-85.

8. F.C. Alvira, D.J.O. Orzi, G.M. Bilmes. "Surface Treatment Analyses of Car Bearings by Using Laser-Induced Breakdown Spectroscopy". Appl. Spectrosc. 2009. 63(2): 192-198.

9. F.C. Alvira, F. Ramirez Rozzi, G.M. Bilmes. " Laser-Induced Breakdown Spectroscopy Microanalysis of Trace Elements in Homo sapiens Teeth". Appl. Spectrosc. 2010. 64(3): 313-319.

10. D.W. Hahn, N. Omenetto. "Laser-Induced Breakdown Spectroscopy (LIBS), Part II: Review of Instrumental and Methodological Approaches to Material Analysis and Applications to Different Fields". Appl. Spectrosc. 2012. 66(4): 347-419.

11. J.M. Vadillo, J.J. Laserna. "Chemical Imaging of Surfaces Using LIBS". In: A.W. Miziolek, V. Palleschi, I. Schechter, editors. LaserInduced Breakdown Spectroscopy (LIBS): Fundamentals and Applications. Cambridge, UK: Cambridge University Press, 2006. Pp. 254-281.

12. T. Flores, L. Ponce, M. Arronte, E. de Posada. "Free-Running and Q:Switched LIBS Measurements During the Laser Ablation of Prickle Pears Spines". Opt. Laser Eng. 2009. 47(5): 578-583.

13. D. Santos Jr., L.C. Nunes, G.G.A. de Carvalho, M. da Silva Gomes, P.F. de Souza, F. de Oliveira Leme, L.G.C. dos Santos, F.J. Krug. "Laser-Induced Breakdown Spectroscopy for Analysis of Plant Materials: A Review". Spectrochim. Acta, Part B. 2012. 71-72: 3-13.

14. J. Kaiser, M. Galiová, K. Novotný, R. Červenka, L. Reale, J. Novotný, M. Liška, O. Samek, V. Kanický, A. Hrdlička, K. Stejskal, V. Adam, R. Kizek. "Mapping of Lead, Magnesium and Copper Accumulation in Plant Tissues by Laser-Induced Breakdown Spectroscopy and Laser-Ablation Inductively Coupled Plasma Mass Spectrometry". Spectrochim. Acta, Part B. 2009. 64(1): 67-73.

15. F.C. Alvira, T. Flores Reyes, L. Ponce Cabrera, L. Moreira Osorio, Z. Perez Baez, G. Vazquez Bautista. "Qualitative Evaluation of Pb and $\mathrm{Cu}$ in Fish Using Laser-Induced Breakdown Spectroscopy with Multipulse Excitation by Ultracompact Laser Source". Appl. Opt. 2015. 54(14): 4453-4457. 